substances was evident; suggesting that the migration of the latter may be independent of the move. ment of water. In all the investigations the results are expressed in absolute quantities per hundred leaves, etc., a method now generally used in this kind of work, so that a more correct impression of the movement of the substances in question is being obtained than would be the case if results were expressed on a dry-weight basis.

In a later series of papers ${ }^{5}$, similar work on Populus pyramidalis and Robinia pseudacacia ${ }^{6}$; Juglans regia, Quercus Robur and Zea Mais ${ }^{2}$; Triticum vulgare ${ }^{8}$; Nicotiana Tabacum ${ }^{9}$; is recorded by Deleano's colleagues. In all cases the three periods of vegetative growth are recognisable, although the duration of the individual periods, and the percentages of materials eliminated during Period (3), naturally show differences in each plant. For example, in Nicotiana there are two well-marked phases of development ; during the first, maximum accumulation of organic and mineral substances coincides with maturity of the main axis and its members, that is, leaves and fruits; then negative migration sets in. But this is arrested by the development of the axillary shoots, and a second period of absorption and assimilation follows, succeeded still later by a second negative migration.

The work of Deleano and his colleagues shows quite clearly that in annual plants the direction of the negative migration in the third period of vegetative activity is from the leaves and stem back into the soil, very little if any being retained in the roots. In biennials, during the second year, the roots act merely as regulators allowing the passage of considerable quantities of mineral substances, so that throughout the whole period during which the aerial portions show the three stages of development, and movement of materials already outlined, the initial content of mineral and total nitrogenous substance in the root itself remains unchanged.

In perennials it is shown that during any one vegetative (leafy) season, nitrogenous and other materials decrease in the stem during the first period of growth of the leaves, accumulate again to their initial value and then remain constant during the second period of protoplasmic stability in the leaves, and remain constant also during the period of negative migration from the leaves. That is, there is no evidence of a further accumulation of these substances in the stem while they are being passed out of the leaves at the end of their vegetative activity. The natural conclusion is, therefore, that in perennials as well as annuals and biennials, most of the substances migrating out of the leaves are returned to the soil, and not stored in either the stem or the root; and that this state of affairs cannot be shown when results are expressed on a dry-weight basis, but only when they are recorded in absolute quantities per hundred plants or parts of plants.

N. L. Penston.

1 NATURE, 136, 268 (1935).

reesco, M., Bul. Soc, Sci. Cluj. Roumanie, 6, 209-220 (1931).

Pflan., 19, Hft. 3 '(1932) Ser. (III), $\mathrm{N}$. T., and Bordeian s Series Title: “Contributiun

in la Studiul Rolului si Functiunii Substantelor Minerali si Organici in Viata Plantei".

- No. 2, Polovrageano, I., Univ, de Bucharest Fac. Farm., May 1933. ? No. 2, Polovrageano, 1., Univ, de Bucharest Fandaresco, E., ibid., June 1934

No. 3, Trandafiresco, E., ibid., June 1934 .

No. 5, Vladesco, I. D., Univ, de Bucharest Lab. de Chim. Anal., 1934 .

\title{
Developments in Cathode Ray Oscillographs
}

$\Lambda \mathrm{T}$ a meeting of the Wireless Section of the A Institution of Electrical Engineers held on March 4, two papers dealing with cathode ray oscillograph tubes were presented, experimental demonstrations being given in each case.

The first paper, by Dr. L. Levy and Mr. D. W. West, was entitled "Fluorescent Screens for CathodeRay Tubes for Television and other Purposes". This paper contains an account of investigations carried out with various materials employed for the screens in cathode ray tubes. The fluorescent and phosphorescent phenomena displayed by a variety of materials are described in detail, and the results of photometric measurements of the illumination of screens of these materials under different conditions of excitation are given. The results show that it has been possible to obtain a zinc sulphide giving approximately white fluorescence, while a mixture of zinc sulphide and zinc cadmium sulphide giving a brilliant white furescence of high intensity has also been prepared. The intense fluorescence of these materials is usually accompanied by considerable phosphorescence, which renders them unsuitable for many practical purposes. The authors have made the discovery, however, that the phosphorescence of zinc sulphide can be prevented by adding a minute trace of nickel-about one part in two million-at the expense of only a very slight reduction of fluorescence.
The second paper, entitled "The Comparative Performance of Gas-Focused and Electron-LensFocused Oscillographs at Very High Frequencies", was read by Mr. L. S. Piggott. This paper describes an experimental investigation of the relative properties of the gas-focused cathode ray tube and that employing an electron-lens system for focusing purposes, at various frequencies up to 1,400 megacycles per second (wavelength about $21 \mathrm{~cm}$.). It appears from the results that the latter type of tube is likely to prove a most useful instrument at very high radio frequencies.

A third paper, "A Cathode-Ray Oscillograph for the Direct Measurement of High-Voltage Transients", by A. K. Nuttall, was published in the February number of the Journal of the Institution of Electrical Engineers. This paper describes a high-speed continuously evacuated cathode ray oscillograph for the recording of high voltage transients, a distinctive feature of the instrument being that impulses of $100 \mathrm{kv}$. ean be applied to the deflecting plates without the use of a potentialdivider. The possibilities of the instrument are illustrated by the results of a brief investigation of the characteristics of a sphere-gap when sparking over on the application of a steep-fronted wave. 